\title{
An Interview with J. Hillis Miller
}

[The occasion for this brief interview was a research seminar organised by the University of Pécs in May 2000. Thanks are due first of all to J. Hillis Miller for his exemplary patience and generosity, and also to Professor Antal Bókay, the organiser of the event. The following interview is the almost entirely unedited transcript of a video recording. - István Adorján]

In one of your essays you exemplify deconstruction, and I am alluding here to another statement of yours, namely that deconstruction, like all other methods of interpretation cannot be defined but only exemplified. Do you exemplify deconstruction as a mode of reading practised by Derrida, de Man, yourself and some others? Would you sketch briefly your relation to the work of these two as well as your own position?

I think that "briefly" is difficult. I was and am with Derrida, a close personal friend of these people, but from the point of view of the theory of their influence on me, it is more a matter of reading. Certainly the reading of the works by both of those people and tending to summarise what they taught was decisive in my own work, even though I would have no hope to imitate their rigour and inventiveness. And even though I have written in general about different authors, that is to say, in general, but not exclusively, on English and American authors, I feel myself still pretty close to them and their theories.

To continue with "weak" definitions of deconstruction, in the same essay you assert that deconstruction is "a currently fashionable or notorious name for good reading as such. All good readers are, and always have been, deconstructionists." Couldn't this be read as a dangerous leap into the transhistorical? Is it avoidable to read this as a kind of pre-emptive universalisation?

Sure, I would deny that. When I made that statement it was meant to be somewhat ironically disarming (probably it didn't work). That is to say, to invite other people to recognise that if they are good readers they are also deconstructionists. Certainly the history of reading is the history of changes, the history of protocols and so on. On the other hand, I would certainly think that what I meant by that was that good reading at any time, at least within the 
Western tradition, involves a certain kind of attention to detail, to rhetorical features and so on, that you would find present already in, say, Aristotle and Plato, in rather different ways. When Plato occasionally talks about a passage from Homer, he is very shrewd in what he says about it. And Aristotle was, among other things, a distinguished literary critic, so that we could still take the Poetics as a kind of model for good reading, even though as I tried to show, there is some strangeness about Aristotle's assumption, for example, that all good work has to be perspicuous, that is to say, you have to be able to see through it, meaning that it has to be of a certain length. But it has always seemed to me that he shows us the mark of genius of a literary theorist or a literary critic, when he chooses in the Poetics the work among Greek tragedies, namely Oedipus the King, that is going to cause his own theory, which is a very rational theory, the most difficulty since it's an irrational play. It is like Austin choosing examples which give his theory difficulty.

You bave always stressed the importance of attending to the text, of undertaking the laborious task of vigilant textual scrutiny. One of your books bears the telling title Theory. Now And Then, that is, in one possible reading, one needs theory only now and then. Or, as de Man also pointed out, one must always start from the experience of reading the text. You said yesterday that what we need is not so much Derrida, for instance (and I think be would agree with you), but a responsible reading. Could you elaborate a bit more on the relation between theory and the practice of reading?

I think reading theory or theoreticians is probably for most people indispensable as a way of learning how to read; good reading does not fall out of the sky. Different people are differently equipped with a kind of curiosity for good reading. It is possible, though, that you don't have to read Derrida or [Kenneth] Burke or anybody else necessarily to be a good reader. But it probably helps, and it helps not so much as to imitate these people as it gives you questions to ask or things to look for. That is to say, you learn, if Derrida in talking about Proust attends to words like prendre, compris and pris, etc., that it might be that you get good results by looking not for that word but looking for recurrent words in another text. That is really not so much the theoretical side of what the theorists say as their methods of reading. And I am not sure that one would be helped all that much, to do a good reading by, say, taking de Man's sentence about the paradigm for all texts consisting of a figural system of figures and deconstruction 
following, and saying: "I am going to demonstrate that this is true for Great Expectations." I am not sure, because you could do that, but it would all too likely to be a kind of mechanical process, just as in earlier years, during the work of Northrop Frye - I used to read, and still read, a lot of journal submissions - there was a period when most or many of them were what seemed to me a kind of mechanical application of Frye's principles. They would start out by saying: "I'm going to show that this is a work that belongs to the Spring or the Summer," or something like that. And this seemed to be not all that helpful. Whereas Frye himself not only was the great maker of this system, the Anatomy, which has vast ambitions to accrue all literature, but the part of Frye's work that really interests me is the essays which are actually readings. For example, there's a quite remarkable essay on Wallace Stevens, and there are others, on Shakespeare and so on. And the quality of those readings is not predictable from the system; it has something to do with something else in Frye. So, theory helps, but not all that much.

According to a notorious claim of yours, the text deconstructs itself, it expresses its own aporia without any belp from the critic. You have also said that deconstruction is conservative as far as the canon goes; the canon is pretty much taken for granted in deconstruction. This was de Man's stance when he admitted in an interview his reluctance to write on contemporary fiction, except, perhaps, Borges or Calvino. Is it the case perhaps that many "postmodern" texts, so to speak, are so overtly and flauntingly self-subversive and self-deconstructing that they make the critic superfluous?

I would think not, absolutely, that is to say they might require different strategies to bring this out, but the critic's work is always that of mediation, of leading the reader back to the text, and I would think that one could safely generalise to say that that could be done for almost any text, but not mechanically and not always in the same way, so that you can figure out for each text what is needed. What I mean by saying that every text deconstructs itself is fairly obvious. That is, it contains its own vocabulary that you can appropriate from the text itself to use as tools of a kind of self-analysis, and that is much more attractive to me than imposing some foreign terminology, for example saying: "I am going to show how this is a system of figures and its deconstruction." And it is in fact consistent with the procedures of Derrida that those notorious terms of his, like différance and dissemination, arise from some particular work of criticism, analysis, and tend to come from the writer in question, and tend then to be, sometimes, referred to 
later, but not deployed as universal terms. So, dissemination was a term he got from Mallarmé, he uses for the analysis of Mallarmé, but he doesn't say that everybody should use this term. It is appropriate for Mallarmé, and it fits the concept of language within Mallarmé, so that it would be impossible to abstract a fixed terminology from Derrida's work. It is not quite so true for de Man, the trajectory was somewhat shorter, but even in de Man there is a change from a phenomenological terminology of subjectivity to a linguistic one, and there is a replacement of a certain kind of linguistic terminology of tropes with a speech act terminology. His terminology was always changing, it is not a kind of fixed system.

In recent years deconstruction has repeatedly been declared by some people passé, defunct and outmoded. One might also think of the rather unjustified and distorting view of deconstruction as being hermetic, abistorical and without sufficient political commitment. On the other hand, you have argued that some versions of what is broadly referred to as cultural studies, while clamorously insisting on the need to historicise and politicise, tend to restrict their focus to the thematic level. In other words, by overlooking the rhetorical-tropological dimension, they paradoxically prove to be more conservative than they believe themselves to be. How do you see present-day cultural criticism?

I am biased, obviously, but I would be willing to say that the strongest part of cultural criticism has been inspired in one way or another by the previous rhetorical criticism, and either consciously or un-self-consciously makes use of it, so that the current developments would be impossible without the prior stage of deconstruction or rhetorical criticism, and they forget that stage in my opinion. So, the work of someone like Judith Butler, though it is not Derridean or de Manian in any narrow sense, nevertheless would be, I think, impossible with its interest in recurrence and so on without her having read those people, and I think she would be willing to admit that. But she appropriates them for her own purposes, and that is the way it ought to be. You cannot go on doing the same thing over and over again. Each new generation of young critics has to find something else to do; it is no use trying to redo the work that Paul de Man or Derrida did, and that is perfectly understandable. On the other hand, you don't want to forget that they existed, and that sometimes is difficult, because you are likely to feel (Bloom was right about this): "this is our shadow, these great figures, I would probably do better if I didn't even read those people, if I pretend they 
didn't even exist." And that would probably be a mistake. A really strong critic would have the ability to read them and do his own type. Jameson would be a good example: somebody who knows this work very well, but does not use it in a straightforward way, nevertheless it is incorporated somehow into his practice. His review essay on Derrida's Marx book was very interesting from that point of view. He did not start as you might think a sort of orthodox Marxist would do, full of hostility, saying, "How could Derrida understand Marx?" It was a very thoughtful and careful, productive evaluation. But that is because Jameson is so strong a person in his own thinking and so productive and creative that he does not have anything to fear from Derrida's influence.

In one of your recent essays ("Marcel on the Telephone") you write about the transformation and indeed the formation of the self and of subjectivity by the new media. In Illustrations you go as far as to claim that a whole new discipline, the discursive field of Cultural Studies, has been in fact shaped and enhanced by multimediality. How do you see the future of literature, the future of criticism, and the future of what in Deleuzean parlance could be called "man-becoming-machine"?

I would say two contradictory things. One: the book is going to be around for quite a long time, people are going to go on reading books, and it is hard to imagine a situation in which universities would not - even for purely historical purposes, in order to understand their own past, the past of their country or the countries that they associate with - read literature, some literature. Literature was so important in the nineteenth century and the twentieth century, and there would be lots of new books written. On the other hand, I do think that we are coming to the end of something and that gradually our culture dominated by print will be replaced, and is being replaced, by other media forms, which are equally worthy of study, but will require different forms of study etc. So, literary study will certainly outlast my time, but I might be a little more anxious if I were a whole lot younger, and I think that is manifest in the fact that so many younger people now want, even if they are trained as literary scholars, to do film criticism, they want to do popular culture and other things. I think that in spite of the claims made that literature still has the same power in our societies, in our countries, I do not think that is really true. I think that is some wishful thinking, and claims made, for example, by my good friend, Phyllis Franklin, who is the executive secretary of the MLA, that people read just as much as they ever did, and that Shakespeare is still taught in all the colleges, and she gathers a lot of 
statistics. On the basis of my knowledge of my own grandchildren, I see that their culture, and I am not in any way denigrating it, is formed by popular music. Sure, they read books, but it is not the centre in quite the same way as it probably was in the nineteenth century, when there was not any alternative. They watch a lot of television, and in the case of my grandson, he does not even watch television or video, he is a computer person. He is one of those "wired" people, and I respect that. But there is no use pretending that his ethos is fundamentally formed by literature, and that seems to me... not dismaying, but interesting. It does not bother me as long as I am allowed to go on reading books 